Pralong, J.A.; Lemière, C.; Rochat, T.; L'Archevêque, J.; Labrecque, M.; Cartier A. Predictive value of nonspecific bronchial responsiveness in occupational asthma. Journal of Allergy and Clinical Immunology 137(2): 412-416, 2016.

\begin{tabular}{|l|l|}
\hline Postprint version & Final draft post-refereeing \\
\hline Journal website & $\underline{\text { http://www.sciencedirect.com/science/journal/00916749 }}$ \\
\hline Pubmed link & $\underline{\text { http://www.ncbi.nlm.nih.gov/pubmed/26220529 }}$ \\
\hline DOI & $\underline{10.1016 / \text { j.jaci.2015.06.026 }}$ \\
\hline
\end{tabular}




\section{Predictive value of non-specific bronchial responsiveness in occupational asthma}

Jacques $A$ Pralong, $M D, M S c^{1,2,3}$, Catherine Lemière, $M D, M S c^{1}$, Thierry Rochat, $M^{3}$, Jocelyne L'Archevêque $\mathrm{RT}^{1}$, Manon Labrecque, MD, $\mathrm{MSc}^{1}$, André Cartier, MD ${ }^{1}$

${ }^{1}$ Department of Chest Medicine, Hôpital du Sacré-Coeur de Montréal, University of Montreal, Montreal, Canada

${ }^{2}$ Institute for Work and Health, Epalinges-Lausanne, Switzerland

${ }^{3}$ Division of Pulmonary Diseases, Geneva University Hospitals, Geneva, Switzerland

Submitted to: Journal of Allergy and Clinical Immunology

Word count (excl. abstract): 2293; 4 Tables

\section{Corresponding author}

Dr Jacques A Pralong

Department of Chest Medicine, Hôpital du Sacré-Coeur

5400 Gouin West

Montreal, Quebec, H4J 1C5, Canada

Tel.: ++41 2131456 04; fax: ++41 213147430

E-mail: jacques.pralong@chuv.ch

Funding source: none 


\section{Abstract (250 words max)}

Background: The diagnosis of occupational asthma $(\mathrm{OA})$ can be challenging and needs a stepwise approach. However, the predictive value of the methacholine challenge has never been addressed specifically in this context.

Objective: To evaluate the sensitivity, specificity, and positive and negative predictive values of the methacholine challenge in OA.

Methods: A Canadian database was used to review 1012 cases of workers referred for a suspicion of OA between 1983 and 2011 and having had a specific inhalation challenge (SIC). We calculated the sensitivity, specificity, and positive and negative predictive values of methacholine challenges at baseline of the SIC, at the workplace, and outside work.

Results: At baseline, the methacholine challenge showed an overall sensitivity of $80.2 \%$ and a specificity of $47.1 \%$, with positive and negative predictive values of $36.5 \%$ and $86.3 \%$, respectively. Among the 430 subjects who were still working, the baseline measures displayed a sensitivity of $95.4 \%$, a specificity of $40.1 \%$, and positive and negative predictive values of $41.1 \%$ and $95.2 \%$, respectively. Among the 582 subjects tested outside work, the baseline measures demonstrated a sensitivity and specificity of $66.7 \%$ and $52 \%$, respectively, and positive and negative predictive values of $31.9 \%$ and $82.2 \%$, respectively. When considering all subjects tested by a methacholine challenge at least once while at work (479), the sensitivity, specificity, and positive and negative predictive values were $98.1 \%, 39.1 \%, 44.0 \%$ and $97.7 \%$, respectively.

Conclusion: A negative methacholine challenge in a patient still exposed to the causative agent at work makes the diagnosis of OA very unlikely. 


\section{Clinical implications}

A negative methacholine challenge in a subject still exposed to the causative agent at work makes the diagnosis of OA very unlikely.

\section{Capsule summary}

This is the first report confirming that the methacholine challenge is a useful tool for clinicians to predict the response to a SIC in workers with a suspicion of OA.

Key words: bronchial responsiveness; methacholine challenge; occupational asthma

\section{Abbreviations used}

OA: $\quad$ Occupational asthma

ACCP: $\quad$ American College of Chest Physicians

NSBR: $\quad$ Nonspecific bronchial responsiveness

SIC: $\quad$ Specific inhalation challenge

Cl: $\quad$ Confidence interval

NPV: $\quad$ Negative predictive value

PPV: $\quad$ Positive predictive value

IQR: Interquartile range 


\section{INTRODUCTION}

The diagnosis of occupational asthma (OA) can be challenging and needs a stepwise approach, as stated in a consensus published by the American College of Chest Physicians (ACCP) (1). One step of this approach consists in confirming the diagnosis of asthma by objective means, i.e. demonstration of reversible airflow obstruction or increased non specific bronchial responsiveness (NSBR) in subjects without airflow limitation (2). Indeed, a negative methacholine challenge $\left(\mathrm{PC}_{20}>16 \mathrm{mg} / \mathrm{ml}\right)$ allows to exclude current asthma with a reasonable confidence in symptomatic subjects(3) However, several studies have shown that subjects with OA may have a normal NSBR when away from work and asymptomatic.(4-6)

A systematic review has reported the pooled estimates for the sensitivity and specificity of NSBR compared to the specific inhalation challenge (SIC) regarding both high and low molecular weight agents. The sensitivity and specificity for high molecular weight agents were 79.3\% (95\% confidence interval [Cl]: 67.7-87.6\%) and 51.3\% (95\% Cl: 35.2-67.2\%), respectively, and 66.7\% (95\% Cl: 58.4-74.0\%) and 63.9\% (95\% Cl: 56.1-71.0\%), respectively, for low molecular weight agents. (7). To improve the diagnostic accuracy in assessing NSBR, several authors have proposed to monitor $\mathrm{PC}_{20}$ at and off work.(8)

The latest ACCP guidelines on work-related asthma state: "the absence of airway hyperresponsiveness on challenge testing has a fairly high negative predictive value (NPV) for current symptomatic asthma, and generally can be used to rule out active disease".(1) However, to our knowledge, this statement has not been verified in a large study designed to assess the predictive value of the methacholine challenge in the 
diagnosis workup of OA, either at the time of the SIC or at any time during the investigation. The first objective of our study was to evaluate the sensitivity, specificity, and NPV and positive predictive values (PPV) of methacholine challenges for the diagnosis of OA in workers with a suspicion of OA. The second aim was to characterize the cases with OA showing normal airway responsiveness before and after the SIC.

\section{METHODS}

\section{Study design and subjects}

We performed a retrospective review of the database of workers referred to the Hôpital du Sacré-Coeur, Montreal, Canada, between 1983 and 2011 for a suspicion of OA. We included all cases of workers who had a SIC and a methacholine challenge on the control day (baseline) and on the last (or following) day of exposure. Procedures are explained in the next paragraph. We had also access to data regarding the monitoring of peak expiratory flows, sputum induction and the methacholine challenge when the challenge test was performed prior to the SIC. Data on working status were available at the time of the SIC. However, the database did not allow to determine if subjects were still exposed to the causative agents while at work, as they might have been moved to another location in the workplace away from exposure. The charts of workers with OA and normal bronchial responsiveness while working or before and after the SIC were reviewed by one of the authors (A.C.) to determine if they were exposed or not to the causative agent.

\section{Procedures}


SICs are considered as the reference standard for diagnosing $O A(1,9)$ and were performed according to standardized methods.(10) In brief, each subject underwent a first day of testing during which he/she was exposed to a control product. Spirometry was performed before and serially for $8 \mathrm{~h}$ after exposure. A methacholine challenge was performed at the end of that day. During the following days, the subject was exposed to the suspected causative occupational agent, either in the laboratory or at the workplace(11) if the exposure could not be reproduced in the laboratory. A second methacholine challenge was performed on the last day or on the day following the end of the SIC in all subjects. OA was defined by $a \geq 20 \%$ fall in FEV1 greater than during the control exposure. Spirometry was performed according to the American Thoracic Society/European Respiratory Society recommendations.(12) Airflow obstruction was defined by a FEV1/FVC ratio $\leq$ 0.7.(13) Prior to the challenge, patients were asked to withdraw medication that could affect the bronchial response (according to their durations of action) except for inhaled corticosteroids which were continued at the same dosage but taken in the evening of each test day (9), to refrain smoking and to avoid foods like coffee, tea, cola drinks and chocolate.

Methacholine challenge testing was performed according to the American Thoracic Society guidelines(14). Increasing serial doses of methacholine were administered until $a \geq 20 \%$ FEV1 decrease or completion of the protocol (highest concentration of methacholine $[128 \mathrm{mg} / \mathrm{ml}]$ reached). The presence of NSBR was defined as a provocative concentration of methacholine that induced a 20\% fall in FEV1 (or $\mathrm{PC}_{20}$ ) $\leq 16 \mathrm{mg} / \mathrm{ml}$ (corresponding to a cumulative dose of $960 \mathrm{ug}$ of methacholine). We chose a cut point of $16 \mathrm{mg} / \mathrm{ml}$ due to its higher NPV compared to $8 \mathrm{mg} / \mathrm{ml}$.(3) Since 
1998, sputum induction has been obtained in most subjects according to the method of Pin et al(15) and processed as previously described.(16)

Subjects underwent skin prick tests with common aeroallergens and, when possible, with specific workplace allergens. Atopy was defined by at least one positive skin prick test (wheal diameter $\geq 3 \mathrm{~mm}$ ) (17).

All the procedures remain sufficiently similar during the whole period to be compared.

\section{Statistical analyses}

All statistical analyses were performed with SPSS 19.0 for Mac OS X (Statistical Products and Service Solution, Inc., Chicago, IL).

The demographic and clinical characteristics of the study population are expressed as the mean and standard deviation, except for data with non-normal distribution, expressed as the median and interquartile range (IQR). Sensitivity, specificity, and the relevant PPV and NPV of the methacholine challenge were calculated in distinct situations, ie, on the control day of SICs (baseline) for all subjects and, when available, while at work and off work. We used logistic regression analysis to evaluate the best predictors of the presence of NSBR among subjects with OA. We describe also a subgroup of subjects with OA, but with normal NSBR both at baseline and following a positive SIC, and compared them to other subjects with OA using a Pearson's chi-square test to compare percentages, an ANOVA test to compare means, and a Mann-Whitney test to compare medians.

\section{Ethics}


The study was approved by the institutional research ethics committee of the Hôpital du Sacré-Coeur, Montreal, Canada.

\section{RESULTS}

\section{Population characteristics}

The charts of 1012 subjects were reviewed. Table 1 shows the baseline characteristics of these cases. A diagnosis of OA was confirmed by a SIC in 278 (27.5\%) cases. For all subjects, the median exposure duration was 7 years, the median symptom duration, 1 year, and the median delay between exposure cessation to the causative agent and testing, 2 months. Nineteen percent of subjects had airway obstruction and $60 \%$ showed increased NSBR at baseline. Thirty percent of subjects were exposed to high molecular weight agents. Among the study population, 430 (42.5\%) were still at work when tested by the SIC (Table 2).

\section{Sensitivity, specificity and predictive values of the methacholine challenge}

The performance of the methacholine challenge in the situations described above is shown in Table 2. At SIC baseline, the methacholine challenge showed a sensitivity of $80.2 \%$ and a specificity of $47.1 \%$, with a PPV and NPV of $36.5 \%$ and $86.3 \%$, respectively. When considering only the 430 subjects who were still working (and in theory exposed - this was confirmed in the 6 workers with $\mathrm{OA}$ and a negative $\mathrm{PC}_{20}$ ) at the time of the SIC, the baseline methacholine challenge displayed a sensitivity of 95.4\%, a specificity of $40.1 \%$, and a PPV and a NPV of $41.1 \%$ and $95.2 \%$ respectively. Among the 582 subjects who had stopped working or had been relocated away from exposure at the time of the SIC with a median interval (minimum-maximum) between 
exposure cessation and SIC of 5 months (0.5-127), the baseline methacholine challenge demonstrated a sensitivity and a specificity of $66.7 \%$ and $52 \%$, respectively, with a PPV and NPV of $31.9 \%$ and $82.2 \%$, respectively. When considering all subjects tested by a methacholine challenge at least once while at work (479 subjects), the sensitivity, specificity, PPV and NPV of the methacholine challenge were $98.1 \%, 39.1 \%, 44.0 \%$ and 97.7\%, respectively (Table 2). Stratification for atopy did not add any precision (data not shown). For the type of agent (high vs low molecular weight) and considering only the NPV, the results are the following: for HMW agents, at SIC baseline, the NPV is $73.6 \%$ and increases to $96.9 \%$ when considering subjects tested by a methacholine challenge at least once while at work; for LMW agents, at SIC baseline, the NPV is $90.5 \%$ and increases to $95.9 \%$ when considering subjects tested by a methacholine challenge at least once while at work (data not shown).

Logistic regression analysis showed that, inhaled corticosteroid use, FEV1, FEV1/FVC $\leq 0.7$, and being still at work at baseline were significant independent predictors for the presence of increased NSBR at baseline among the 278 subjects with OA (Table 3) with odds ratios (OR) of 2.7 (95\% Cl: 1.2-5.9), 0.6 (95\% Cl: 0.3-1.0), 0.2 (95\% Cl: 0.0-1.0), and 6.2 (95\% Cl: 2.7-14.4), respectively.

\section{Subjects without NSBR before and after SIC}

Among the 278 subjects with OA, 23 showed no increased NSBR both at baseline and post-SIC (Table 4). These subjects received less frequently inhaled corticosteroids, had less often airway obstruction, and were less often working at the baseline SIC compared to other cases with OA ( $P$ value $<0.05)$. However, among these 23 subjects, 11 had an increased NSBR on at least one occasion before the SIC testing while exposed at work. 
Among the remaining 12 subjects with a $\mathrm{PC}_{20}>16 \mathrm{mg} / \mathrm{ml}$ ever, none had a methacholine challenge while still exposed to the causal agent at work. Fourteen of the 23 subjects had sputum induction performed before and after the SIC (data not shown): 3 were unable to produce sputum and 10/11 showed an increase in the eosinophil count postSIC (median increase in eosinophil count, 6.5\%; IQR: 41.2\%). Nine of the 23 subjects (39.1\%) were exposed to flour.

\section{DISCUSSION}

To our knowledge, this is the first study demonstrating the usefulness of the methacholine challenge to predict the response to a SIC in a large sample of workers with a suspicion of OA and using the SIC as the reference standard for its diagnosis. The results confirm two recommendations published by the ACCP.(1) First, a negative methacholine challenge when the subject is at work makes the diagnosis of OA highly unlikely since the negative predictive value of the test in this population is $95.2 \%$.

Second, it emphasizes the importance of performing the diagnosis work-up when the subject is still at work as the NPV of the baseline methacholine response at the time of the SIC improves from $82.2 \%$ when he/she is off work to $95.2 \%$ at work. This NPV increased to $97.7 \%$ when considering workers tested by a methacholine challenge at least once when still at work (including those at work during the baseline methacholine challenge and those off work during the baseline methacholine challenge, but with a previous challenge when at work).

The value of performing methacholine challenge testing while at work is confirmed in the multivariable analysis in which the best predictor for the presence of increased NSBR is being at work at the time of the SIC (OR: 6.2; 95\% Cl: 2.7-14.4). 
Among the other predictors, the use of inhaled corticosteroids, the level of baseline FEV1 and the presence of airway obstruction are consistent with the fact that these parameters are associated with the presence of asthma. Another important point is the repetition of methacholine challenges over time in subjects at work. In those with one negative methacholine response while at work, increasing the number of methacholine challenges may improve the NPV of the test by reducing false-negative results. The latter may be explained by several reasons: technical error; medication taken inadvertently; no exposure for several days to the causative agent, with less than a week being enough to normalize NSBR.(18) However, we cannot give a precise response, eg, the number of methacholine challenges needed, as the database lacked this information.

Most workers with OA showed bronchial hyperresponsiveness either before or at least after the SIC. However, 23 workers with a diagnosis of OA had a NSBR in the normal range (PC20>16 mg/ml) both at baseline and post-SIC. This is likely explained by the fact that their NSBR disappeared following cessation of exposure. Most who had sputum induction (10/11) showed evidence of eosinophilic airway inflammation following the SIC. Indeed, Lemiere at al. have shown that bronchial eosinophilia may precede changes in bronchial responsiveness after a SIC.(19) Furthermore, 11/23 subjects had at least one positive methacholine challenge before SIC testing, while none of the remaining subjects had a methacholine challenge performed when still exposed to the causative agent. This supports the value of monitoring $\mathrm{PC}_{20}$ while at work, which may improve its NPV.

The limitations of our study are the lack of data related to the symptoms of most workers and their real exposure at the time of the methacholine challenge. The strengths of the study are the large sample size and the use of the reference standard challenge (SIC) to diagnose 
OA.

These data demonstrate that the methacholine challenge has a high NPV for excluding the diagnosis of $\mathrm{OA}$ in a worker still at work, using a $\mathrm{CP}_{20}>16 \mathrm{mg} / \mathrm{ml}$ as the cut-off point of normality. However, there is still a place for clinical judgment, coupled with the monitoring of peak expiratory flows and, if possible, sputum induction, to decide if there is still a need to perform a SIC, which remains the reference standard, in these patients. Whenever possible, the diagnostic work-up of workers, including methacholine challenges, should be done while the patient is still exposed at work. 


\section{REFERENCES}

1. Tarlo SM, Balmes J, Balkissoon R, Beach J, Beckett W, Bernstein D, et al. Diagnosis and management of work-related asthma: American college of chest physicians consensus statement. Chest 2008;134:1S-41S.

2. Lougheed MD, Lemiere C, Ducharme FM, Licskai C, Dell SD, Rowe BH, et al. Canadian thoracic society 2012 guideline update: Diagnosis and management of asthma in preschoolers, children and adults. Can Respir J 2012;19:127-164.

3. Cockcroft DW. Direct challenge tests: Airway hyperresponsiveness in asthma: Its measurement and clinical significance. Chest 2010;138:18S-24S.

4. $\mathrm{Nam} \mathrm{YH}, \mathrm{Kim} \mathrm{JI}, \mathrm{Um} \mathrm{SJ}$, Lee SK, Son $\mathrm{CH}$. Absence of hyper-responsiveness to methacholine after specific bronchial provocation tests in a worker with hydroxyapatiteinduced occupational asthma. Allergy Asthma Immunol Res 2011;3:135-137.

5. Lemiere C, Weytjens $\mathrm{K}$, Cartier A, Malo JL. Late asthmatic reaction with airway inflammation but without airway hyperresponsiveness. Clin Exp Allergy 2000;30:415-417. 6. Banks DE, Barkman HW, Jr., Butcher BT, Hammad YY, Rando RJ, Glindmeyer HW, et al. Absence of hyperresponsiveness to methacholine in a worker with methylene diphenyl diisocyanate (mdi)-induced asthma. Chest 1986;89:389-393.

7. Beach J, Rowe BH, Blitz S, Crumley E, Hooton N, Russell K, et al. Diagnosis and management of work-related asthma. Evid Rep Technol Assess (Summ) 2005:1-8.

8. Chan-Yeung M, Malo JL. Occupational asthma. N Engl J Med 1995;333:107-112.

9. Vandenplas O, Suojalehto H, Aasen TB, Baur X, Burge PS, de Blay F, et al. Specific inhalation challenge in the diagnosis of occupational asthma: Consensus statement. Eur Respir J 2014;43:1573-1587. 
10. Pepys J, Hutchcroft BJ. Bronchial provocation tests in etiologic diagnosis and analysis of asthma. Am Rev Respir Dis 1975;112:829-859.

11. Rioux JP, Malo JL, L'Archeveque J, Rabhi K, Labrecque M. Workplace-specific challenges as a contribution to the diagnosis of occupational asthma. Eur Resp J 2008;32:997-1003.

12. Miller MR, Hankinson J, Brusasco V, Burgos F, Casaburi R, Coates A, et al. Standardisation of spirometry. Eur Resp J 2005;26:319-338.

13. Celli BR, MacNee W, Force AET. Standards for the diagnosis and treatment of patients with copd: A summary of the ats/ers position paper. Eur Resp J 2004;23:932946.

14. Crapo RO, Casaburi R, Coates AL, Enright PL, Hankinson JL, Irvin CG, et al. Guidelines for methacholine and exercise challenge testing-1999. Am J Respir Crit Care Med 2000;161:309-329.

15. Pin I, Gibson PG, Kolendowicz R, Girgis-Gabardo A, Denburg JA, Hargreave FE, et al. Use of induced sputum cell counts to investigate airway inflammation in asthma. Thorax 1992;47:25-29.

16. Pizzichini E, Pizzichini MM, Efthimiadis A, Dolovich J, Hargreave FE. Measuring airway inflammation in asthma: Eosinophils and eosinophilic cationic protein in induced sputum compared with peripheral blood. J All Clin Immunol 1997;99:539-544.

17. Pepys J. "Atopy": A study in definition. Allergy 1994;49:397-399.

18. Cockcroft DW, Mink JT. Isocyanate-induced asthma in an automobile spray painter. Can Med Assoc J 1979;121:602-604. 
19. Lemiere C, Chaboilliez S, Trudeau C, Taha R, Maghni K, Martin JG, et al. Characterization of airway inflammation after repeated exposures to occupational agents. J Allergy Clin Immunol 2000;106:1163-1170. 
Table 2. Sensitivity, specificity, and positive and negative predictive values of the methacholine challenge

\begin{tabular}{|c|c|c|c|}
\hline & $\begin{array}{l}\mathrm{PC}_{20} \leq 16 \\
\mathrm{mg} / \mathrm{ml}\end{array}$ & $\begin{array}{l}\mathrm{PC}_{20}>16 \\
\mathrm{mg} / \mathrm{ml}\end{array}$ & Total \\
\hline \multicolumn{4}{|c|}{$\mathrm{PC}_{20}$ at baseline (control day) $(\mathrm{n}=1012)$} \\
\hline $\mathrm{OA}$ & 223 & 55 & 278 \\
\hline Non OA & 388 & 346 & 734 \\
\hline Sensitivity & 0.802 & PPV & 0.365 \\
\hline Specificity & 0.471 & NPV & 0.863 \\
\hline \multicolumn{4}{|c|}{$P_{20}$ at baseline AND at work $(n=430)$} \\
\hline OA & 125 & 6 & 131 \\
\hline Non OA & 179 & 120 & 299 \\
\hline \multicolumn{4}{|c|}{ 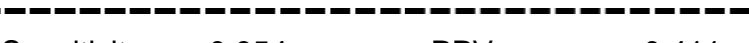 } \\
\hline Sensitivity & 0.954 & PPV & 0.411 \\
\hline Specificity & 0.401 & NPV & 0.952 \\
\hline \multicolumn{4}{|c|}{$P_{20}$ at baseline AND off work $(n=582)$} \\
\hline $\mathrm{OA}$ & 98 & 49 & 147 \\
\hline Non OA & 209 & 226 & 435 \\
\hline$-2-2$ & & & \\
\hline Sensitivity & 0.667 & PPV & 0.319 \\
\hline Specificity & 0.520 & NPV & 0.822 \\
\hline \multicolumn{4}{|c|}{$\mathrm{PC}_{20}$ measured at least once while at work $(\mathrm{n}=479)$} \\
\hline $\mathrm{OA}$ & 154 & 3 & 157 \\
\hline Non OA & 196 & 126 & 322 \\
\hline Sensitivity & 0.981 & PPV & 0.440 \\
\hline Specificity & 0.391 & NPV & 0.977 \\
\hline
\end{tabular}

OA: occupational asthma; PPV: positive predictive value; NPV: negative predictive value 
Table 3. Multivariable model for the presence of non-specific bronchial responsiveness at baseline in the 278 cases of occupational asthma

\begin{tabular}{l|c|c|c} 
& $\beta$ & $P$-value & OR (95\% Cl) \\
\hline Age $>$ 40 years & 0.184 & 0.768 & $0.9(0.4-2.1)$ \\
& & & \\
Female & 0.464 & 0.365 & $1.6(0.6-4.3)$ \\
Smoking status & 0.172 & 0.439 & $1.2(0.8-1.8)$ \\
Atopy & 0.094 & 0.857 & $1.1(0.4-3.1)$ \\
& & & \\
ICS use & 1.0 & $\mathbf{0 . 0 1 2}$ & $2.7(1.2-5.9)$ \\
FEV1 (L) & -0.571 & $\mathbf{0 . 0 4}$ & $0.6(0.3-1.0)$ \\
& & & \\
FEV1/FVC $\leq 70 \%$ & -1.621 & $\mathbf{0 . 0 4 4}$ & $0.2(0.0-1.0)$ \\
Exposure duration > 7 years & 0.228 & 0.6 & $1.3(0.5-2.9)$ \\
Symptom duration > 1 year & 0.223 & 0.578 & $1.3(0.6-2.7)$ \\
HMW agent exposure & -0.214 & 0.569 & $0.8(0.4-1.7)$ \\
& & & \\
At work during baseline challenge & 1.827 & $<0.001$ & $6.2(2.7-14.4)$
\end{tabular}

ICS: inhaled corticosteroids; HMW: high molecular weight; OR: odds ratio; $\mathrm{Cl}$ : confidence interval 
Table 4. Subjects with occupational asthma, with and without baseline and post-specific inhalation challenge bronchial hyperresponsiveness

\begin{tabular}{|c|c|c|c|c|c|}
\hline & $\begin{array}{l}\text { Baseline } \\
>16 \mathrm{mg} / \\
\mathrm{N}=23(8 .\end{array}$ & st-SIC PC 20 & $\begin{array}{l}\text { Baselin } \\
\text { SIC PC } \\
N=255\end{array}$ & $\begin{array}{l}\text { /or post- } \\
6 \mathrm{mg} / \mathrm{ml} \\
7 \%)\end{array}$ & $P$-value \\
\hline $\begin{array}{l}\text { Mean age, years (SD) } \\
\text { Median exposure duration, } \\
\text { years (min-max) }\end{array}$ & $\begin{array}{c}37.1 \\
8.0\end{array}$ & $\begin{array}{c}(8.1) \\
(0.0-26.0)\end{array}$ & $\begin{array}{c}38.8 \\
7.0\end{array}$ & $\begin{array}{c}(10.9) \\
(0.0-48.0)\end{array}$ & $\begin{array}{l}0.458 \\
0.395\end{array}$ \\
\hline $\begin{array}{l}\text { Median delay between } \\
\text { cessation of exposure and } \\
\text { testing, months (min-max) }\end{array}$ & 4.0 & $(0.0-11.0)$ & 0.0 & $(0.0-127.0)$ & 0.854 \\
\hline $\begin{array}{l}\text { Median symptoms duration, } \\
\text { years (min-max) }\end{array}$ & 2.0 & $(0.0-10.0)$ & 2.0 & $(0.0-28.0)$ & 0.274 \\
\hline Female, $\mathrm{n}(\%)$ & 7 & $(30.4)$ & 75 & $(29.4)$ & 0.918 \\
\hline Smoking status, n (\%) & & & & & 0.590 \\
\hline - Never & 9 & (39.1) & 104 & $(40.8)$ & \\
\hline - Ex-smoker & 10 & $(43.5)$ & 87 & (34.1) & \\
\hline - Current smoker & 4 & (17.4) & 64 & (25.1) & \\
\hline ICS use, $\mathrm{n}(\%)$ & 6 & (26.1) & 137 & (53.7) & 0.011 \\
\hline Atopy $^{*}, \mathrm{n}(\%)$ & 21 & $(95.5)$ & 195 & $(79.9)$ & 0.074 \\
\hline FEV1 $\leq 80 \%$ pred, $\mathrm{n}(\%)$ & 0 & $(0)$ & 59 & $(23.2)$ & 0.009 \\
\hline FEV1/FVC $\leq 70 \%, \mathrm{n}(\%)$ & 1 & $(4.3)$ & 64 & $(26.0)$ & 0.020 \\
\hline $\begin{array}{l}\text { Professional rhinitis, } \mathrm{n}(\%) \\
\text { Agents, } \mathrm{n}(\%)\end{array}$ & 6 & $(26.1)$ & 68 & $(26.7)$ & 0.952 \\
\hline - HMW & 15 & (65.2) & 127 & (49.8) & 0.080 \\
\hline - LMW & 7 & $(30.4)$ & 126 & $(49.4)$ & \\
\hline - Multiple & 1 & $(4.3)$ & 2 & $(0.8)$ & \\
\hline $\begin{array}{l}\text { Type of asthmatic reaction, } \\
\mathrm{n}(\%)\end{array}$ & & & & & 0.170 \\
\hline -Immediate & 17 & (73.9) & 147 & $(57.7)$ & \\
\hline -Late & 5 & (21.7) & 53 & (20.8) & \\
\hline -Dual & 0 & $(0)$ & 45 & $(17.6)$ & \\
\hline -Atypical & 1 & $(4.3)$ & 10 & $(3.9)$ & \\
\hline Per-SIC PC $_{20}$ decrease $\geq 3.2$ & 6 & (26.1) & 97 & (38.0) & 0.256 \\
\hline $\begin{array}{l}\text { Exposed at work during } \\
\text { baseline SIC, } n(\%)\end{array}$ & 0 & $(0.0)$ & 133 & (52.2) & $<0.001$ \\
\hline
\end{tabular}

SIC: specific inhalation challenge; OA: occupational asthma; ICS: inhaled corticosteroids; HMW: high molecular weight; LMW: low molecular weight; SD: standard deviation

*Atopy is defined as at least one positive reaction to skin prick tests to common allergens. 